\title{
Control of Time, Cost and Quality of Construction Project Management
}

\author{
$H$ M A Asfoor ${ }^{1,2, ~ *, ~} A$ A T AL-Jandeel ${ }^{3,4}, K K$ Igorevich $^{5}$ and $L A$ Ivanovna $^{6}$ \\ ${ }^{1}$ Postgraduate Student, Department of Automobile Transport, Faculty of Motor Transport, South Ural State University, Lenin \\ Avenue, 76, Chelyabinsk, 454080, Russian Federation. \\ ${ }^{2}$ Deputy Chief Engineer 9 Diwaniya Investment Commission (DIC), Diwaniya, Iraq. \\ ${ }^{3}$ M.Sc student of the Department of Price Formation in Construction and Industry, Ural federal University named after the first \\ president of Russia B.N.Yeltsin, Miraulitsa, 17, Yekateringburg, 620002, Russian Federation. \\ ${ }^{4}$ Ministry of communication (MOC), Baghdad, Iraq. \\ ${ }^{5}$ Head of the Department of Price Formation in Construction and Industry, Ural federal University named after the first \\ president of Russia B.N.Yeltsin Miraulitsa, 17, Yekateringburg, 620002, Russian Federation. \\ ${ }^{6} \mathrm{M}$.Sc student of the Department of Price Formation in Construction and Industry, Ural federal University named after the first \\ president of Russia B.N.Yeltsin Miraulitsa, 17, Yekateringburg, 620002, Russian Federation.
}

Email: iraqieng2003@yahoo.com* , anas_star2001@yahoo.com

\begin{abstract}
One of the most common methods of projects management of the implementation of construction projects is the Project Management Triangle (PMT), this method give the balance between the three heads of this triangle time, cost and quality. In addition, the main principle is integrating the design and construction phases in a parallel way, where the basic elements of the project time, cost and quality will not be influenced by each other. some of the projects are established by some construction companies in developing countries in the world have been failed to manage and solve the weaknesses points in these projects and sometimes failures due to the increase in cost or the low level of quality, as found by the field survey. Therefore, the research aim is to develop and apply the general planning mechanisms of the project to get the development of projects detailed plans to control the factors time, cost and quality of the executed works. The main results of the study were, depending on the choice of the target function, can give early or late start times by linear programming solutions for all nodes or events in the project domain; so the early start times of the project should be determined first. The supposed project domain includes a number of nodes ranging from $(1-\mathrm{m})$, as node (1) led to represent the opening of the project activity work and node $(\mathrm{m})$ represent the end of the project and that will be found the balance between the (PMT) elements.
\end{abstract}

Keywords: Project Management Triangle (PMT), Project Management, time, cost, quality, developing countries and stockholders.

\section{Introduction}

The efficiency evaluation of the construction companies of different profiles can be determined based on the performance, which has a long-term and short-term perspective. The strategies of projects management of modern construction and investment complexes involve solving the actual problem of increasing efficiency or quality and reducing costs. However, now there is an objective need to improve these strategies, from quality improvement by managing the cost funds in the shortest period of implementation, [1]. Let's go into more detail that supports the engineering project management methodology the detail on each of these elements of the methodology. The logic of any work needs firstly the clarification of its purpose and how can support the main purpose, $[2,3]$.

Should be regarded that the selection of definition of the purpose of the management process is the most complex work which will face the top management of companies. Usually, the management appliance, especially coordinating with quality control and work efficiency with the cost management, led to understanding the purpose of the company considerably briefly. The shortage of necessary useful skills and competencies should replace by skills from other areas - jurisprudence, office work, and social philosophy - leads to a disfigured opinion of the actual course of business in the company, the goal setting and the possibility of achieving the targets, [4]. So unacceptable to say that quality control management is ineffective, pointing to a distorted view of the substance of the company's work domain that directly will cause damage to the company of a different domain, [5]. Substitution of role-playing activity establish the positive environment of the effective managerial process when the document passage experiences external differences, but in tradition the management is deadened, tumbling down to ritualizing processes and replacing a role producing functional with the formal process. The company acquires losses because its activities are actually neglected, and the engaging in of the management

${ }^{*}$ Corresponding author: Iraqieng2003@yahoo.com 
equipment and the production of documents stripped of an objective sight, conquering the rational activity to the incessant multiplication of the same forms and trading with the direct function of management on the residual principle, [6-9].

The implementation activities are chosen by some construction companies in developing countries of the world have been marred by short-comings and sometimes failures due to the increase in cost or the low level of quality, as designated by the field survey, furthermore, the difficulty of work methods and the many types of waste of construction materials, that will lead to the inadequate quantity of experience in this field despite its increasing influence. Therefore, the research aims to develop and apply the general planning mechanisms of the project with the development of detailed plans to control the time factor in combination with controlling the cost of the project and the quality of the executed works, [10].

\section{Management success in construction projects}

The success of the project can be achieved by implementing the design requirements to reach the purpose that the project established due to it. Project management must reach the equilibrium between the highly efficient with lower cost in the shortest time, and project preferences must be recognized by providing all sources for project management in this integration between these elements and suitable use to complete any section with optimal use of time when implementing.

Commence in establishing the different environments of work for employees to get the effective work team, that can be applied by:

1. The leader staff selection on the top of management administration should be selected carefully.

2. Creating a work environment in which a friendly atmosphere prevails.

3. Holding the coordination meetings between the project parties, including implementers and designers, and supervision and follow-up to change designs, solve problems and obstacles, expedite the use of alternatives and reduce time.

4. Providing all the supplies and equipment necessary for the establishment and success of the project according to pre-prepared plans to reduce wastage in time and cost. This can be done by choosing sources of raw materials close to the worksite with ease of processing upon request.

5. The projects in which project management was used in the implementation. It was noted that time is considered the influential element in the project first, quality second, and cost third, which must be balanced between the three elements.

Due to the focus on the time factor in construction projects, the following negatives usually appear:

a. The quality level is influenced by poor implementation because of speed.

b. The percentage of wastage in construction materials will Increase.

c. Spending workers' energy by employing them for overtime, which negatively affects the quality of workers' productivity and production.

On the other hands, the project success can be divided into four dimensions of time-dependent. The first one is the period time that the project needs performance and right after project completion such as completion on time and finance resources. The second dimension can be estimated after a short period when the project has been carried to the customer or users and it is focused more on satisfaction, the function of the product and technical specifications. While the third thing can be estimated after an important level of sales has been done in one to two years and it will show the organization performances it like the guaranty period. The last dimension can be evaluated only after three to five years of project finish, it is about preparing for the future and the maintenance plans [16]. A project can be considered totally successful if the project achieves the professional performance specifications and purposes, also a high level of stakeholder's satisfaction for the project outcomes among the company, project team and service recipients, [17]. The successful completion of cost, time, and quality objectives was due to the project management success which is direct; project success was purchased with the final project objectives [18].

\section{Master Plan Preparing}

The rule of achieving a standard central plan for the implementation of the construction project in an expedited method depends on the integration of all the main elements of production and implementation. The stability of the production process is the main purpose of it due to reducing the duration of the activities, taking into account the determinants of cost and quality required for the project and being in full agreement with the requirements of the standard of the designer and the stakeholders in the same time [11].

The stimulated implementation of the project in addition to the central concern in the fact that these variables can be understood, adjusted or fixed, 
including raw materials, instruments, types of equipment or work activities. In this study, possibility to suggest project planning in an accelerated way of implementation, Fig (1).

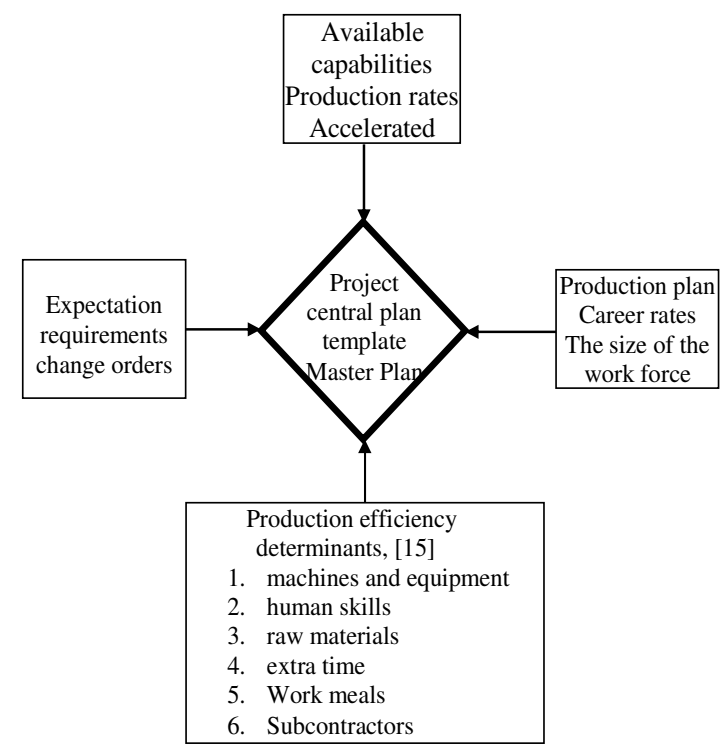

Fig. 1. The proposal of the central plan for the accelerated implementation of the project.

The use of this model in the general planning of the company's management will provide opportunities to respond to the needs that depend on the following variables, [14]:

1. Change in the size of the labor force.

2. Take advantage of overtime.

3. Add necessary work meals.

4. Managing in bearing possible difficulties.

5. Use of subcontractors to divide the workload.

6. Expecting the possibilities of change orders from the employer.

7. Expect variations in market prices to meet needs.

8. Take advantage of potential technological development.

\section{Planning by Linear Programming}

Linear programming can be defined as a mathematical modelling technique that uses to find the level of operational effectiveness for the purpose of achieving a target with certain constraint's influencing. Most of the stakeholders of the project play the main role to select the main activities that are used as a tool to manage the project implementation to reach the best way to achieve the company's goals that are subjected to constraints required by the environment and conditions of implementation. These conditions can be specific resources such as raw materials, labor, machinery, cash flow, and these constraints can be general determinants of accelerated implementation such as the work of the sequence or engineering specifications and others, [12].

There are several stages of modelling and analysis of linear programming in projects management, such as follows, [13]:

1. Problem Formulation: This stage starts data collection and identification of limitations with the operational study of the problem and its system.

2. Mathematical Modeling: It is the description of the problem or projects implication gaps through mathematical modelling, certainly this model represents the system that will be analyzed while retaining the probability of following the mathematical model.

3. Model Testing \& Analysis: It is the collection and analysis of the solution of the model and its sensibility to various factors of the system.

4. Implementation: It is the use of the established system as a foundation for the stockholder's process and not as a substitute for the one who decisionmaking.

Depending on the decision-making experiences to get the shortest way to the target function, here the linear programming solutions can be used early or late start times for each event or node in the project schedule, where the early start times of the project must first be fixed. The project network is assumed to include a number of nodes ranging from $1-m$, as node 1 represents the opening of the project activities and node $m$ represents the end of the project, as shown in Eq. (1), Objective Function, [11].

$$
M_{i n}=\sum_{i=1}^{m} x_{i}
$$

Where:

$M_{\text {in }}$ - Objective Function;

$m$ - represents the end of the project,

$x$ - The project objectives.

This function is subject to the following parameters:

$$
\boldsymbol{x}_{\boldsymbol{j}}-\boldsymbol{x}_{\boldsymbol{i}} \geq \boldsymbol{D}_{\boldsymbol{i j}}
$$

For each pair of nodes of the activity $(i, j)$ as well as specified

$$
x_{i} \geq o \quad \text { for } \quad 1 \leq i \leq m
$$

These determinants assure that there is enough time departing each node from the other in the series of shares between the activities described by the node. 
Furthermore, to the fact that the objective function decreases the values of $x i$, the early ending times will get as an instant solution. Also, the late start times can be determined by replacing the goal function, Eq. (2):

Where

$$
M_{i n}=\left\{m \cdot X_{m}-\sum_{i=1}^{m} x_{i}\right\}
$$

$X_{m}$ - is the total time required to complete the project,

It is found useful to achieve the lowest possible value of $X_{m}$ so that its symbol should always remain positive because the multiplication factor $m$ in $X_{m}$ assures that the objective function remains positive to ensure that realistic values are obtained for outcomes analysing will produce to the stockholders.

\section{Conclusion}

1. The general planning of the project it turns out that the importance of building levels of planning is commensurate with the nature of the rapid implementation tools and includes detailed plans to control all these processes while supporting and taking into consideration the factors of time, cost and quality.

2. The aims of the development of the central plan model for rapid implementation to improve the entire regulatory process in the project by setting the objectives, resources, increase the production rates and the necessary skillfulness into the scheduled applying, in a manner that ensures its practical ability to complete the project.

3 . This plan is aiming to get the effective control production levels by defining an element of a special system to control the production processes in the project by building a model for procedures that determine the scope of administration, measure performance, compare it with standards and targets results, recognize variations, and take suitable and ready improving measures to reach the highest possible level of workability.

4. The control of time and cost has been resulted to get excellent outcomes by applying the use of modern computer technologies such as linear programming, which can be explained in more detail to the investors or the stockholders to make the central plan more clearly reduce the project fulfilment period and the critical activities of time pressure technology program at the lowest possible cost to control both time and cost.

5. The employer's provision of the cash flow is one of the important things because it is necessary to pay the financial dues on time without delay to all project workers, material suppliers, equipment contractors and others to ensure the flow of work within the schedule of timetable.

6. The paper resulted in the adoption of the accelerated implementation process in critical activities of circumstances that require to complete the project within a specific short period, with the need to provide experienced and efficient employees for this type of project, with committing the construction companies to submit detailed plans and the central plan for the implementation of the project to the employer within the suggestions for the purpose of developing these companies and upgrading their performance. In addition, Obligating governmental companies or private construction companies and technical departments staffs to use modern technologies and software to control time and cost in planning accelerated applying plans.

\section{References}

1. Zilberova, I., Petrov, K., \& Artsishevsky, M. (2020, February). Actual problems of management quality control of a construction company. In IOP Conference Series: Materials Science and Engineering (Vol. 753, No. 4, p. 042020). IOP Publishing.

2. Shirina E, Gaybarian O, Myasischev G 2017 Effective management of construction company in terms of linguistic communication IOP Conf. Series: Earth and Environmental Science 90012077.

3. Klyuchnikova O V, Kostyuchenko V V, Pobegaylova E V 2014, Organization management from psychological components to its structuring (Rostov-Don).

4. Klyuchnikova O V 2013 The effectiveness of the project excavate for laying utility networks Inženernyj Vestnik Dona 4 URL:http://www.ivdon.ru/ru/magazine/archive/ n4y2013/2072.

5. Encyclopedia of the Don region The jubilee album devoted 70 years the Rostov region (Rostov-Don).

6. Keeling R P 2007 Horizontal and Vertical structures: The dynamics of organization in higher education (Liberal Education) 22-3.

7. Masse P 1962 Optimal investment decisions (Englewood Cliffs N.J.).

8. Oleynik P P 2001 Organization of construction, Conceptual framework, models and methods, information and engineering systems Profizdat (Moscow).

9. Pobegaylov O A, Voronin A A 2013 The key component of the human resource management system Inženernyj Vestnik Dona 3 
http://www.ivdon.ru/ru/magazine/archive/n3y20 $13 / 1778$.

10. Thomas G. Atkinson. "Civil Engineering of Buildings - History of San Diego" Journal, 2002, Vol. 48.

11. Calabrese, A. (2013). Master in strategic project management (European), a worldwide experience. Procedia-Social and Behavioral Sciences, 74, 488-497.

12. Bazaraa, M., and Jarvis J." Linear Programming and Network Flows" John-Wiley and Sons., New York, 1977.

13. Mohammed, T., Haron, N., Alias, A., Muhammad, I. B., \& Baba, D. (2018). Improving cost and time control in construction using building information model (BIM): A review.

14. Shaqour, E. N. (2021). The role of implementing BIM applications in enhancing project management knowledge areas in Egypt. Ain Shams Engineering Journal.

15. Khodeir, L. M., \& Nessim, A. A. (2018). BIM2BEM integrated approach: Examining status of the adoption of building information modelling and building energy models in Egyptian architectural firms. Ain Shams Engineering Journal, 9(4), 1781-1790.

16. Shenhar, A.J, Dvir. D, Levy. O, Maltz. A C. (2001), Project Success: A Multidimensional Strategic Concept, Journal of Long Range Planning, Vol 34, issues 6, page 699-725.

17. Wite, A., (1988). Measurement of project success. International Journal of Project Management 6 (3), 164-170.

18. Pheng, L., Chuan, Q., (2006). Environmental factors and work performance of project managers in the construction industry. International Journal of Project Management 24, 24- 37. 